\title{
Correction to: Classification of Normal, Ictal and Inter-ictal EEG via Direct Quadrature and Random Forest Tree
}

\author{
Enas Abdulhay ${ }^{1} \cdot$ Maha Alafeef $^{1} \cdot$ Arwa Abdelhay $^{2} \cdot$ Areen Al-Bashir $^{1}$
}

Published online: 9 February 2018

(c) Taiwanese Society of Biomedical Engineering 2018

\section{Correction to: J. Med. Biol. Eng. (2017) 37:843-857 https://doi.org/10.1007/s40846-017-0239-z}

The article "Classification of Normal, Ictal and Inter-ictal EEG via Direct Quadrature and Random Forest Tree", written by Enas Abdulhay, Maha Alafeef, Arwa Abdelhay, Areen Al-Bashir was originally published Online First without open access. After publication in volume [37], issue [6], page [843-857] the author decided to opt for Open Choice and to make the article an open access publication.
Therefore, the copyright of the article has been changed to (C) The Author(s) [2018] and the article is forthwith distributed under the terms of the Creative Commons Attribution 4.0 International License (http://creativecommons.org/licenses/ by/4.0/), which permits use, duplication, adaptation, distribution and reproduction in any medium or format, as long as you give appropriate credit to the original author(s) and the source, provide a link to the Creative Commons license, and indicate if changes were made.
The original article can be found online at https://doi.org/10.1007/ s40846-017-0239-z.

\section{Enas Abdulhay}

ewabdulhay@just.edu.jo

1 Department of Biomedical Engineering, Faculty of Engineering, Jordan University of Science and Technology, P.O.Box 3030, Irbid 22110, Jordan

2

\footnotetext{
Department of Water and Environmental Engineering, Faculty of Natural Resources Engineering, German Jordanian University, P.O.Box 35247, Amman 11180, Jordan
} 